Donald C. Rowat (Hrsg.)

\title{
Administrative Secrecy in Developed Countries
}

Columbia University Press, New York, 1979 XXIV und 364 S., DM 63,90

Bei dem anzuzeigenden Band handelt es sich um die englische Ubersetzung einer vom Internationalen Institut für Verwaltungswissenschaften in Brüssel veranlaßten rechtsvergleichenden Studie aus der Serie "Studies in Administrative Procedures", deren französische Fassung im Jahre 1977 unter dem Titel "Le Secret Administratif dans les Pays Développés" veröffentlicht wurde. Die zwölf Länderberichte, von Universitätsprofessoren und Ministerialbeamten verfaßt, sind nach einem einheitlichen Gliederungsschema aufgebaut, soweit dies mit den Besonderheiten der behandelten Länder vereinbar war. Diese strukturelle Homogenität der Berichte erleichtert das Anliegen, wirklich die Möglichkeit zu einem Vergleich der unterschiedlichen Rechtsordnungen zu bieten, ohne zu verhindern, daß eine Fülle von Informationen über die jeweiligen Länder - auch außerhalb des eigentlichen Berichtsthemas -, etwa über Geschichte und Rechtstradition, Ambiance, Gestimmtheit usw., ausgebreitet werden kann. Die Länderberichte sind in vier Gruppen eingeteilt:

1. Skandinavien mit Berichten über Schweden (S. Holstad), Finnland (T. Modeen), Dänemark (N. Eilschou Holm) und Norwegen (A. Frihagen);

2. Westeuropa mit Belgien (E. Jorion), Frankreich (J. C. Boulard),Großbritannien (R. E. Wraith) und Bundesrepublik Deutschland (M. M. Bullinger);

3. Osteuropa mit Ungarn (S. Berényi/T. G. Nagy) und Jugoslawien (M. Petrovic̀);

4. Nordamerika mit Kanada (Donald C. Rowat) und USA (M. J. Singer).

Eingangs gibt der Herausgeber, Professor der Politischen Wissenschaften an der Carleton University in Ottawa, einen vergleichenden Uberblick dessen, was in den Länderberichten zusammengetragen worden ist, und eine konzise Würdigung der von den unterschiedlichen Rechtsordnungen gefundenen Lösungen. Die Berichte streben eine Grenzbestimmung zwischen gerechtfertigter und unzulässiger Geheimhaltung an. Sie suchen nach Kriterien für eine befriedigende Berücksichtigung legitimer Bedürfnisse der Wissenschaft, der Wirtschaft und der allgemeinen Offentlichkeit einerseits, der Notwendigkeit andererseits, aus spezifischen und sachgemäßen Gründen bestimmte Informationen vertraulich oder "streng geheim" zu behandeln. Demgemäß untersuchen die sieben Abschnitte der Berichte: Hintergrundinformationen; allgemeine Rechte auf öffentlichen Zugang zu Informationen der Verwaltung einschließlich Vorschriften über die Arten von Informationen, die geheimzuhalten sind; die "Inhaber" von Verwaltungsinformationen (Regierungs- und Verwaltungsstellen); die Empfänger von Verwaltungsinformationen (Parlamente und Gerichte, Medien, Wissenschaftler, an Verwaltungsverfahren beteiligte Bürger); Informationsverfahren (Speicherung und Übermittlung, Sicherheitsklassifizierung von Dokumenten, Sperrung und Freigabe von Informationen); allgemeine Entwicklungstendenzen und kürzlich erfolgte oder vorgeschlagene Änderungen zum Recht der Informationsfreiheit. Die untersuchten Länder bilden zwei "Rechtsfamilien ": Fünf Staaten haben ein besonderes (Verfassungs)Gesetz über ein - erzwingbares - Recht auf 
Informationszugang und eine abschließende Aufzählung der Ausnahmen (auswärtige Angelegenheiten, nationale Sicherheit, Verhinderung und Verfolgung von Straftaten, Schutz der Persönlichkeitssphäre unter besonderer Berücksichtigung der automatischen Datenverarbeitung, interne Arbeitspapiere, einige wirtschaftliche Angelegenheiten der Exekutive und privater Unternehmen). Sieben Staaten folgen vorerst primär dem traditionellen Prinzip der Geheimhaltung nach Ermessen des Informationsinhabers. Zwar gibt es in dieser "Familie" eingehende Programme der Offentlichkeitsarbeit zur Information der Bürger; kürzlich sind auch beachtliche Schritte in Richtung auf erleichterten Zugang der Offentlichkeit zu Dokumenten gemacht worden. Aber das Prinzip, Verwaltungsinformationen geheimzuhalten und den Zugang zu Dokumenten nur nach Ermessen der Exekutive zu gewähren ("principle of discretionary secrecy"), wird auch dann aufrechterhalten, wenn nicht legitime Interessen, sondern die Angst vor öffentlicher Kritik gegenüber Verwaltungsmißständen im Spiele sind. Allerdings wird dieses Prinzip zunehmend in Frage gestellt, weil es die volle Entwicklung der Demokratie verhindere; es diene nur noch dem eigenen Nutzen von Regierung und Verwaltung und führe zu Mißtrauen und Angst auf Seiten der Bürger. Die "Pflicht zu informieren" könne leicht eine "Freiheit zur Propaganda" werden, bei der die Offentlichkeit es schwer habe herauszufinden, ob exekutives Fehlverhalten vorliege. Rowat kommt zu dem Ergebnis, nur eine völlige Aufgabe des traditionellen Prinzips der "diskretionären Geheimhaltung" könne der Informationsfreiheit zum Durchbruch verhelfen. Dazu seien vier Regelungen erforderlich:

- der allgemeine Grundsatz freien öffentlichen Zugangs zu Dokumenten der Exekutive muß gesetzlich gesichert sein;

- legitime Ausnahmen müssen eng und spezifisch aufgezählt werden;

- es muß ein Beschwerderecht gegenüber einer unabhängigen Einrichtung (Gericht oder Ombudsman, am besten beide) geben;

- alle Dokumente sollten registriert werden, so daß ihre Existenz und Identität festgestellt werden kann.

Es überrascht wenig, daß es schwierig war, für Entwicklungsländer geeignete Berichterstatter zu finden; der Untersuchungsgegenstand dürfte zur Zeit in den entwickelten Staaten eine größere Priorität genießen. Der Herausgeber hofft, daß die ausgewählten Länder aus letzteren einen repräsentativen Querschnitt bilden. Auch unter ihnen sind die Unterschiede etwa zwischen Skandinavien und den anderen Berichtsländern oder zwischen Bundesstaaten und Einheitsstaaten beträchtlich. Entwicklungsführer dürfte Schweden sein, über dessen Regelung festgestellt wird, das Recht auf Zugang zu Informationen werde sehr selten mißbraucht und behindere die tägliche Arbeit der Verwaltung nicht "to any degree worth mentioning" (S. 14).

Walter Wiese 